\title{
Study on the Effects of Haze Weather on Rural Tourism-A Case of
}

\author{
Langfang \\ Xiuwei Huang ${ }^{1}$ \\ ${ }^{1}$ Langfang Teacher's University, Langfan, HeBei, 065000 \\ 346591653@163.com
}

KEYWORDS: Haze Weather; Rural Tourism; Langfang

\begin{abstract}
As a new form of tourism, Langfang rural tourism gets attention of more and more people of all ages. In recent years, the rural tourism has a rapid development, but due to the late start, there are still many problems to be solved. They are government not know the place, backward management; planning unscientific, single product; severe ecological damage; to promote its marketing strategy is not in place; rural poor infrastructure; lower service quality; their own way, there is no scale effectiveness. To improve Langfang rural tourism, the key is the government should play a leading role in Langfang rural tourism development and course of business to do guidance, supervision and management. Langfang Government to adhere to the majority of rural leisure tourism area in the first place the interests of farmers, fully integrated local rural tourism resources Langfang actual, out of a "government enterprise + farmers + Travel Association," the road of sustainable development.
\end{abstract}

\section{Introduction}

Since 1995, the implementation of five-day work week system, people's leisure time increased, coupled with our road traffic increasingly developed, as well as including the paragraphs stated reason that makes Langfang rural tourism development faster and faster. In recent years, the Chinese government for Langfang rural tourism have also organized many activities and issued a number of documents, for example, 1998, 1999, 2002, 2006 and 2007 are related to the theme of tourism Langfang rural leisure tourism, and 2006 and 2007 have issued a document on the promotion of rural tourism Langfang development; and the activities of the High-level Forum Langfang rural tourism in 2009 and 2010, also held a large number, this does not enumerate . October 2010, the Ministry of Agriculture and the National Tourism Administration jointly issued "to carry out the national leisure agriculture and rural tourism demonstration counties and national leisure agriculture demonstration activities to create views," this document is to promote the development of rural tourism in Langfang, promotion of agricultural and industrial structure adjustment of rural economic structure, accelerate the construction of new socialist countryside. So, with the continuous economic and social development, increasing people's needs, how to better promote rural tourism Langfang forward, we continue to meet people's growing material and cultural needs, we continue to explore and become thought. 
Rich tourism resources in the vast rural areas, rich in tourism resources, both natural landscape, but also cultural landscape; both the agriculture, forestry, animal husbandry and fishery resources, there are all kinds of cultural resources. Many local travel times with a certain seasonal undertaken Langfang rural tourism with a certain seasonal, mostly because of those rural agricultural production activities have spring, summer, autumn and winter points, summer, autumn season compare agricultural production activities more travel relatively hot; winter and spring farming leisure, tourism is relatively cold. There's northern region, for example, when the autumn and winter cold, people travel to participate in Langfang rural tourism activities is minimal. Langfang participatory rural tourism activities traveler behavior and not just a single tourism activities, visitors can also participate in production work, the delicious taste of country, the river fishing, boating lake, picking vegetables and fruits and other activities. Harmony between man and nature is human nature rural landscape for a long time to adapt and transform nature and create harmony of natural and cultural landscape, while maintaining the original natural state, but also a strong local flavor. Rural This "ancient, beginning, really, earth," the local characteristics, so Langfang rural tourism has close to nature, back to nature and the characteristics of harmony between man and nature. This is to meet the Chinese traditional leisure and human thinking a return to human instinct. Regional tourism distribution is well known and almost every country has regional differences, resulting in different rural areas forming a distinctive Murai environment. For example, the difference between both the north and south of the rural countryside, but also rural mountainous plains of the points, in addition Murai environment between the various ethnic groups in some areas is also very different. Langfang rural tourism has obvious regional. Popularity and source markets showing a trend of diversification of the economy with the development of modern society, people have more and more disposable income and leisure time, Langfang rural tourism has not only the affluent city dwellers or patent, gradually developed into a way of mass tourism. Wages in the cities, wealthy and working-class and rural part of the population composed of Langfang rural tourism consumer customer base, which both young, but also the elderly. The relatively low level of consumption occurred in Langfang rural tourism rural areas, compared with urban leisure and tourism, the low level of tourist spending, it is precisely for this reason that makes the Langfang rural tourism source market gradually showing popularity and diversity trend.

\section{Development Situation of Langfang Rural Leisure Development Travel}

In recent years, Langfang rural tourism as a new approach to development of tourism, agriculture and tourism and other resources together, setting off yet another opportunity for the development of tourism. Langfang world experience rural tourism development is already quite mature, Langfang rural tourism development although very rapidly, but due to a late start in the development process, there are still many problems.

Tourism is a strong industry association, involving catering, transport, accommodation, communications and other infrastructure construction and ecological environmental protection. Leadership in some areas busy with the performance and profit-oriented operators want to become rich, and did not take full account of its own resources and tourist market, an enthusiasm herd alone, blind development Langfang rural tourism resources, not its rural Langfang tourism resources planning and planning, but shoddy, without regard to the quality of hastily implemented, tourism projects in the same area appear to repeat, did not highlight its own characteristics, compete with each other, inefficient; in addition, some of the villagers due to the relatively low cultural level, the issues to consider not in-depth, see others engaged in Langfang rich rural tourism up, also followed the rush to start the tour operator, by virtue only of their own farmland, orchards, pastures and other 
promote tourism, resulting in low-level product, homogeneity is serious, facilities and poor environment, the products are not culture, not focusing on mining Langfang rural folk customs resources, struggling to survive after a period of time gradually closed. When Langfang rural tourism development, should take into account not only the neighboring village or town tourism development project is similar, neighboring county tourism products should also avoid duplication of development, otherwise it will affect the local rural tourism can Langfang sustainable development. Langfang blind development of rural tourism resources will not only cause a huge waste of manpower, material and financial resources, and will damage the local natural environment, affect the quality of life of local people.

Their own way have resulted in some of the resources and funds cannot form an effective force, developed Langfang rural tourism projects are often small, and in the course of business will be weak brand awareness of the situation is more prone; In addition, the development of rural tourism resources Langfang, most of fragmentation will only focus on the development of Langfang rural agricultural resources, while ignoring the more wealthy economic, artistic and historical value of the cultural resources of the excavation, the expense of other rural Langfang resources development and utilization, which is our rural development Langfang leisure Tourism in facing the problem.

\section{The Path to Develop Langfang Rural Tourism under Haze Weather}

Langfang rural tourism development the most important thing is to broaden the channels to raise funds to ensure there is sufficient funding to infrastructure projects and Langfang rural tourism in the past. First, the government should actively promote farmer participation in rural tourism Langfang raise funds, the farmers involved in fund raising mode can be cash, land or other forms of transfer of shares and other participating shares farmers can be achieved by the end of dividends, enjoy the village or township other types of subsidies. Second, the government can be in the form of investment, the introduction of the enterprise into the Langfang rural tourism development in the past, some companies can implement tax incentives to attract more conducive to the development of local rural tourism businesses, organizations to discuss investment cooperation project. Finally, the government should seriously implement the higher level of rural tourism development policy documents issued, should be combined with local conditions to develop supportive policies for rural tourism development in Langfang; for the disbursement of funds to support the higher level, the government should set up a rural tourism project support special fund, the superiors and local support funds for the development of local rural tourism project. This special fund prior to each rural tourism project allocation, the Government and the relevant administrative departments to the Joint Expert full evaluation, development can be carried out before we can confirm the transfer of funds, the management of the funds earmarked to follow the principles. Langfang rural tourism development for a region is a systematic project, involving multi-stakeholder, in which there would a reasonable allocation of interest to be able to ensure that rural tourism Langfang healthy and sustainable development.

Rural tourism resources protection and rational development and utilization is obtained Langfang rural tourism foundation for sustainable development. Rural tourism resources development should adhere to the principle of local specialties, sightseeing tourists to the countryside, to experience rural life and rural folk to understand the history and culture are based on authenticity rural tourism resources as the basis, which is compared to rural tourism and urban tourism It possesses unique. In addition, we develop rural tourism resources to follow the principles of protective development, this principle is also reflected in the concept of sustainable rural development. Protective Development requires developers to fully understand the local history, this will ensure that rural tourism historical 
authenticity, integrity and unique style charm continuity of life; in the development process to maintain the countryside surrounding native landscape and residential buildings reflect local style.

In order to achieve healthy, stable and sustained development of rural tourism, the relevant government departments need to establish and improve various rules and regulations, Langfang rural tourism industry supervision and management. The local government should first develop in accordance with national requirements for the local development of rural tourism demonstration zone, leisure agriculture, rural tourism demonstration sites Langfang standard, start local leisure agriculture and rural tourism demonstration project Langfang as soon as possible, the demonstration counties, demonstration township (town) construction business model as lead and guide local leisure agriculture and rural tourism Langfang important measure of development, which is conducive to rural tourism Langfang upgrade product quality, enhance the competitiveness of Langfang rural tourism market.

\section{Conclusion}

Langfang rural tourism is a village full use of resources, to provide a new form of leisure tourism for visitors, it has rich resources, popularization and diversification of source markets, tourists' behavior and participation in regional and other characteristics, through rural scenery, rural folk, historical and cultural sites, ecological sightseeing agriculture, forestry and animal husbandry and fisheries production activities as well as leisure farms and other rural resource development of distinctive Langfang rural tourism projects. It is to the development of rural idyllic tour, folk custom tour, farm or farm tours and participation in other forms of travel experience to meet the various needs of tourists.

\section{REFERENCE:}

[1] Weaver B D, Lawton J L. Resident Perception in the Urban-rural Fringe. Annals of Tourism Research, 2001, 28(3):439-458.

[2] Allen L R, Hafer H R, Long P T. Rural Residents' Attitudes Toward Recreation and Tourism Development. Journal of Travel Research, 1993, 31(4): 27-33.

[3] Hegarty C, Przezborska L. Rural and Agri-tourism as A Tool for Reorganizing Rural Areas in Old and New Member States-A Comparison Study of Ireland and Poland. International Journal of Tourism Research, 2005, 7(2): 63-77.

[4] Knowd I. Tourism as a Mechanism for Farm Survival. Journal of Sustainable Tourism, 2006, 14(1): 24-42. 